\title{
OCCIPITO-CERVICAL FUSION FOR ODONTOID FRACTURE
}

\author{
Major M. S. OWEN-SMITH, F.R.C.S., F.R.C.S. (Edin.), R.A.M.C. \\ Military Hospital, Terendak, Malaya.
}

FRACTURES of the odontoid process of the axis are not common, but certainly they do not fall into the category of rare curiosities, as is still taught in most undergraduate and postgraduate centres. The belief that the fracture is always associated with sudden death, and therefore is more of forensic than clinical importance, is difficult to replace. Any surgeon dealing with trauma, especially from traffic accidents, may expect to see several cases during his career.

Over 250 cases have been reported to date with a great increase in incidence over the last twenty years. At least the same number may be assumed to have occurred but have not been described in the literature.

Six cases were treated at Royal Herbert Hospital, Woolwich in the two years 1964 and 1965. This is the Army Orthopaedic Centre, and it is probable that all fractures of this nature from the Army in the United Kingdom and abroad, would have been sent there for definitive treatment.

We are convinced that the fracture is even more common than the figures given suggest. The fracture remains undiagnosed in many cases simply because suspicion is not cast on the odontoid after all injuries to the neck and head. It is true to say that once the possibility is considered, standard radiographs of the region will always reveal a fractured odontoid when present and any associated atlanto-axial subluxation. Early recognition and treatment of the fracture carries a good prognosis, whereas omission of diagnosis carries a high risk of progressive neurological complications and a definite risk of a fatal outcome should further trauma occur.

\section{Case 1}

\section{Case Summaries}

Male aged 19 years. Involved in a traffic accident in Germany in July 1963. After radiographic examination a fracture of the odontoid process of the axis was diagnosed. He had no neurological disturbance and was placed in a Minerva plaster. He was admitted to Royal Herbert Hospital, Woolwich six weeks later when the plaster was removed and radiographs confirmed the presence of an undisplaced transverse fracture of the base of the odontoid. The Minerva plaster was replaced for a further three months; at that time radiographs disclosed the fracture to be ununited, and that movement of the atlas forwards on the axis took place during flexion of the neck. In November, 1963 occipito-cervical fusion was performed using iliac crest strips and cancellous bone to the occiput, atlas and axis. The head and neck were immobilised for three months, when radiographs in flexion and extension confirmed that the fusion was sound. A Strudwick frame was worn for a further three months.

One year after fusion the range of cervical movements was almost full and he had no disability.

\section{Case 2}

Male aged 45 years. Hit on the back of the head by a $30 \mathrm{lb}$. jerrican in 1944 and unconscious for a few minutes. He had a painful stiff neck but quickly recovered. 
In 1961 he developed intermittent paraesthesia of the fingers of the right hand which gradually got worse. In 1962 he developed numbness and aching over the shoulders, right arm and right thigh. In March 1962 the left arm became affected. At British Military Hospital, Rinteln, radiographs showed an ununited fracture of the base of the odontoid with marked forward subluxation of the atlas on the axis. He was treated with a collar which made his symptoms worse, and he developed weakness of both hands.

In May, 1962 at Colchester Military Hospital, the atlas was wired to the axis and a bone graft applied. There was some temporary improvement in power and sensation. The head and neck were immobilised in a Minerva plaster. At the end of 1962, radiographs showed that the atlas had slipped forwards again but was relatively stable. By the end of 1963 he had developed progressive weakness of all four limbs, increased tone and reflexes, bilateral extensor plantar responses, paraesthesia of both hands and widespread sensory loss. He was admitted to Royal Herbert Hospital, Woolwich and in January, 1964 the atlas was wired into place again and occipito-cervical fusion performed. The subluxation was. only partially reducible. The operation was done while he was in the Minerva plaster. He was immobilised for three months in this and for a further three months in a Strudwick frame, by which time the radiographs showed the graft to be resorbed between atlas and occiput, but with sound fusion between atlas and axis with no movement. Three years later he had 50 per cent of neck movements but was in full time employment. His neurological signs had not progressed. The head was still unstable, however, and the occiput was regrafted to the axis in January, 1967.

\section{Casè 3}

Male aged 32 years. Involved in a traffic accident in Germany in November, 1963 and unconscious or disorientated for two weeks. He made a slow recovery and developed some personality changes. In 1964 he was seen at Colchester Military Hospital, where radiographs showed a fracture through the base of the odontoid process of the axis, with forward subluxation of the atlas on the axis during flexion of the neck. He was admitted to Royal Herbert Hospital, Woolwich in April, 1964 when it was noted that the reflexes in the left arm were increased. In May, 1964 occipito-cervical fusion was performed. The upper part of the graft resorbed and was regrafted in October, 1964; this was successful.

\section{Case 4}

Male aged 19 years. Fell into a ditch in Germany in June, 1964, knocking his head forwards and acutely flexing his neck. The following day his head and neck were painful on the slightest movement. Admitted to British Military Hospital, Munster, where radiographs showed a fracture of the base of the odontoid process of the axis, with anterior and lateral shift of the atlas on the axis. He was placed in a plaster collar in July, 1964. One month later he was admitted to Royal Herbert Hospital, Woolwich, where it was noted that one inch of nodding movements was allowed by the collar. There was no neurological abnormality. Radiographs confirmed the fracture, and flexion caused forward subluxation of the atlas. A Minerva plaster was worn for three months and a Strudwick frame for a further month.

A year later he had slight pain and stiffness of the neck. Radiographs showed 
fibrous union of the fracture with no forward shift of the atlas but allowing 20 degrees tilt of the odontoid process on flexion.

\section{Case 5}

Male aged 26 years. Involved in a traffic accident in British .Guiana, as the front seat passenger, his head hitting the roof of the car. He had an upper brachial plexus lesion of the left side and weakness of both arms and one leg. He complained of dysphagia and later of neck pain. Radiographs revealed a fractured odontoid process of the axis with marked forward subluxation of the atlas. After six days skull calipers were inserted and traction applied on a Stryker frame. He later had a tracheostomy.

He was flown back to England and admitted to Royal Herbert Hospital, Woolwich. On October, 1964 the subluxation was reduced at open operation and the posterior arch of the atlas wired to the axis. Occipito-cervical fusion was then carried out. A week later traction was removed and a Minerva plaster applied. He coughed fluid up through the tracheostomy after drinking and although a tracheo-oesophageal fistula could not be demonstrated a temporary gastrostomy was done. After ten days he had so improved that the tracheostomy and gastrostomy tubes were removed.

Six weeks after the operation he was allowed home on sick leave. On the train journey he became increasingly short of breath and was laid down on his back; by the time the train stopped at a station and a doctor was called he was found to be dead.

Post mortem examination showed that he had died from apiration of vomit. The occipito-cervical fusion was sound.

\section{Case 6}

Male aged 42 years. Traffic accident in Cyprus in November, 1965. He was the front seat passenger and sustained a compound depressed fracture of the right frontal region. Seven days later he complained of neck pain and dysphagia. Radiographs showed a fracture of the odontoid process of the axis with marked forward subluxation of the atlas. There were no abnormal neurological signs.

He wore a plaster collar for three weeks and was then flown back to England and admitted to Royal Herbert Hospital, Woolwich. On 30th November, 1965 occipitocervical fusion was carried out. A Minerva plaster was worn for three months and a cervical brace for six weeks. Eight months after operation the graft was sound and he had a full range of cervical movements, except that rotation was reduced by 30 degrees.

\section{Anatomy}

The odontoid process projects upwards from the body of the axis. It is conical in shape, about $1.5 \mathrm{~cm}$ long, and is constricted at its lower end where it joins the axis and where it lies in contact with the strong transverse ligament. At this point the odontoid is narrowest and weakest. Blockey \& Purser (1956) showed radiographs of sections, demonstrating that the cortex was thinner and cancellous trabeculition less at the base. Below the apex, the sides of the odontoid are flattened where the alar ligaments are attached. These ligaments are strong rounded cords which pass upwards, laterally and backwards, to be inserted into rough impressions on the medial side of the occipital condyles.

The alar ligaments are tight at the extremes of flexion, extension and rotation of 
the head; it is thought that they exert enough leverage to break off the odontoid at its base when these extreme movements are suddenly exceeded.

Between the odontoid and the anterior arch of the atlas lies a synovial joint, whilst a second synovial joint lies between the posterior aspect of the base of the odontoid and the transverse ligament of the atlas.

\section{Production of fracture}

In the reports of cases in which the odontoid was fractured it had been noted that the cause was generally severe violence forcing the head into extreme positions of flexion, extension or rotation. This violence was almost always due to falls on the head from a height or to traffic accidents. The fracture has, however, resulted from minor trauma. Lambotte (quoted by Corner 1907) described a woman who had suddenly extended her head whilst sewing, and Willard \& Nicholson (1941) reported a case resulting from a fight between children. Direct violence is rarely recorded as a cause but Scott (1904) described a woman who was hit on the back of the neck with a stick; she had little disability but ten days later she died from tetanus; post mortem examination showed a fractured odontoid together with fractures of both arches of the atlas. Amyes and Anderson (1956) successfully treated a case of gross atlanto-axial subluxation following a neck blow with a "blackjack" which fractured the odontoid.

Wüsthoff (1923) believed that the transverse ligament broke off the odontoid as the atlas and skull were forced forwards on the axis.

Jefferson (1920) postulated that in forced extension of the atlanto-occipital component on the axis, the odontoid might be broken off by the anterior arch of the atlas. He also described what he called the " mechanism of transmitted force". When the head is forced downwards on the vertebral column, the atlas is squeezed between the occipital condyles above and the axis below, and, owing to the obliquity of its articular surfaces, the wedge-like lateral masses tend to slide outwards. This tendency is resisted by the anterior and posterior arches 'which bind the lateral masses together, and also by the strong transverse ligament which not only holds the odontoid in place, but acts as a tie-bar for the lateral atlantal masses. This ligament is extremely strong. As the lateral masses are forced apart the atlas is deformed in shape from an oval having its long axis from before backwards, to one with the long axis from side to side. Thus the arches may break - the posterior one more often as it is thinner and weakened by the grooves for the vertebral arteries and sub-occipital nerves-or the anterior arch may break off the odontoid. Twenty-five cases of complicated atlantal fracture quoted included two fractures of the odontoid and the anterior arch of the atlas, six of the odontoid and posterior arch, and seven of the odontoid and both arches.

\section{Attempts to reproduce fracture}

Stephen Smith (1871) was unable to fracture any part of the atlas or axis by dropping cadavers on their heads from a height. Fritzsche (1913) was able to fracture the odontoid process only once in a series of experiments designed to imitate judicial hanging. In this case the head was distracted from the atlas, and presumably the alar ligaments broke off the odontoid. Wagner and Stolper (1898) were unable to produce a fracture of the odontoid in their experiments on cadavers; Blockey and Purser (1956) were also unsuccessful. 


\section{Judicial hanging}

It is commonly thought that judicial hanging causes a fracture of the odontoid process, or, alternatively, that the transverse ligament of the atlas ruptures and allows the odontoid to " pith" the spinal cord. This is not so. Haughton (1866) wrote that hanging caused a depressed fracture of the neural arch of the axis. Wood Jones (1913) described the lesions in criminals hanged in Rangoon jail as a bilateral fracture of the pedicles of the axis resulting in complete transection of the cord. Camps (1965) and Simpson (1965) describe the lesion as fractures of the pedicles of the axis, 3rd or 4th cervical vertebrae with gross stretching of the spinal cord so that it is transected or torn off from the medulla. It is interesting to note that of 50 doctors asked to describe the lesion causing death in judicial hanging, only one gave the correct answer. $\mathrm{He}$ had experience of certifying death after hanging. The other 49 all blamed a fractured or ruptured transverse ligament, and it is easy to see how the fracture required a reputation for causing immediate, sudden death.

\section{Diagnosis}

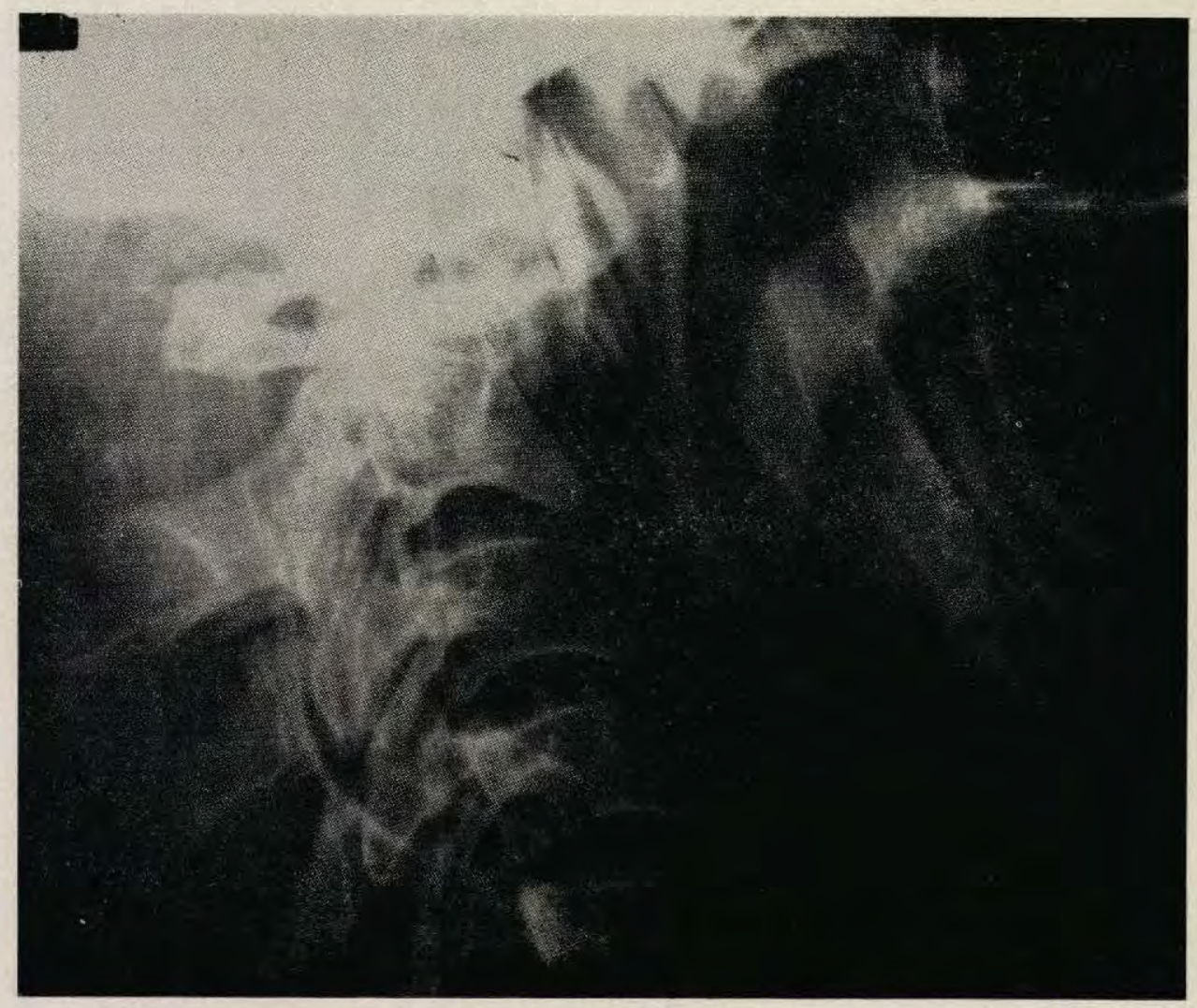

Fig. 1. Fracture of the odontoid with forward subluxation of the atlas.

A fracture of the odontoid must be suspected in every patient who has had a cervical 
injury. In a few cases the only complaint is of a slightly stiff neck, and the only sign is some diminution of movement, although generally, symptoms and signs are more marked.

Often the patient cannot move the head because of pain and supports it on the hands; muscular spasm is marked. The head may be held in abnormal positions and many authors describe these. This is most marked with associated fractures of the atlas. Rotation is invariably very painful, if possible at all, but again this is not diagnostic of a simple fracture of the odontoid as it may be caused by isolated atlas fractures. Occasionally there is marked prominence of the spine of the axis because the fracture has allowed the atlas to dislocate forwards on the axis. This is vividly described by Gibson (1885). Very occasionally a deprèssion, or a ridge, may be felt on the posterior pharyngeal wall at the level of the palate, when the anterior arch of the atlas has been displaced forwards or backwards. Pilcher (1910) first described this sign.

Pain on swallowing may be a symptom, even when no displacement of the atlas can be appreciated, and palpation shows no bulging of the posterior pharyngeal wall. This is recorded in the personal experience of Dr. Lund (1928) and the assoeiation of dysphagia with thickened speech is mentioned by Corner (1907). Anaesthesia, paraesthesia or hyperaesthesia in the occipital region are relatively common symptoms, and are generally due to involvement of the greater occipital nerve as it passes below the posterior arch of the atlas. Sicard \& Rogers (1916) and Jefferson (1920) described this as occurring when the odontoid is fractured and also in isolated fractures of the posterior arch of the atlas.

\section{Complications}

If the force causing a fracture of the odontoid process continues to act, the atlas is subluxated backwards or forwards and, therefore, the cord may be severely damaged or severed, causing immediate or rapid death. Such a case is described by Dupont (1876) in which a man jumped out of a fourth floor window. He was found to be alive but completely paralysed, and died four hours later. At post mortem examination the cord was found to be stretched by the atlas which was dislocated forwards. The majority of cases described in the last century ended in death within a few hours or days, and it is easy to see how the fracture obtained such a bad reputation. Less severe injuries to the cord may cause immediate neurological signs ranging from paraesthesia to quadraplegia. Most of these cases show a backward displacement of the atlas (Blockey \& Purser 1956) and after adequate treatment with traction the abnormal signs disappear completely or improve. Forward displacement which occurs suddenly or with slow progression, is associated with late neurological complications. Paraplegia or other severe neurological complications have occurred up to fourty-four years after the original injury. An instructive case is that of Cone \& Turner (1937) who told of a doctor involved in a car accident in which he sustained multiple injuries and was unconscious for two days. He recovered quickly but complained of a stiff neck which was treated by massage. The stiffness persisted to some extent and sixteen years later he slipped whilst performing a difficult forceps delivery. He immediately developed numbness and tingling in his hapds and weakness of arms and legs; his neck was held rigid by painful muscular spasm. He showed increased reflexes and bilaterial extensor plantar responses. Radiographs demonstrated an old fracture of the odontoid with forward subluxation of the 
atlas on the axis, and at operation the posterior arch of the atlas was found pressing on the cord. The occiput and upper six cervical vertebrae were fused successfully.

Further slip of the atlas can occur even whilst in traction and plaster, such as in case 4 of Blockey \& Purser (1956), which they then had to fuse.

The most dramatic complication is sudden death occurring at an interval after an accident which has caused a fracture of the odontoid process. Such a case is that described by Gibson (1885) of a man who fell down a hillside. When found, he showed a marked flexion deformity of the neck with a very prominent spine of the axis and marked muscular spasm. He was in severe pain. Following manual reduction the deformity disappeared. The patient was laid flat with the head held immobile between sandbags, and as he had difficulty with swallowing he was fed fluids only. On the twenty-third day he begged his wife for some solid food, on which he promptly choked. He sat up sharply in bed to cough properly, and dropped dead with the reappearance of the same deformity. Post morten examination showed the spinal cord tightly stretched over the sharp edge of the axis by the almost completely dislocated atlas and the attached odontoid.

Similar cases are reported in the papers of the majority of the writers of the last century and up until about 1910. Costes (1855) and Bernstein (1903) described comparable cases who died ten to eleven weeks after injury, and who were found at post mortem examination to have marked callus formation compressing the cord.

Very rarely the fractured odontoid process has become involved in an osteomyelitis and the whole process has been extruded through the pharynx (Syme, 1826), or neck (Bayard, 1870).

\section{Prognosis}

If the patient survives the initial injury which caused the fracture of the odontoid process then the prognosis is good.

Up until 1910, out of 23 cases described 19 died. Since that date only 10 have died as a direct result of the fracture out of about 220 cases. This date is a landmark, for this is when Mixter \& Osgood (1910) performed the first operation for internal fixation of the fractured odontoid. Taken in conjunction with the increasing use of diagnostic $\mathrm{X}$-rays, doctors suddenly realised that the fracture was not always fatal and could be diagnosed and treated successfully.

\section{Treatment}

If treatment is started immediately after injury and there is no atlanto-axial subluxation, the head and neck may be immobilised using a Minerva plaster or the Halo traction apparatus (Thompson, 1962; White, 1966). Otherwise the initial treatment of a fractured odontoid is skeletal traction applied to the skull by means of a caliper, such as Crutchfields. The treatment thereafter is divided into two schools of thought.

Conservative. Blockey \& Purser (1956) describe the method used in their cases, which involved immobilising the head and neck by continuous traction for six weeks. A Minerva plaster was then applied with the patient still in traction and with the caliper incorporated into the plaster. This remained on for a further six weeks.

Out of their 9 adult cases, 4 however, failed to unite by bone, and in the 3 in which flexion and extension radiographs were done there was some movement at the fracture 


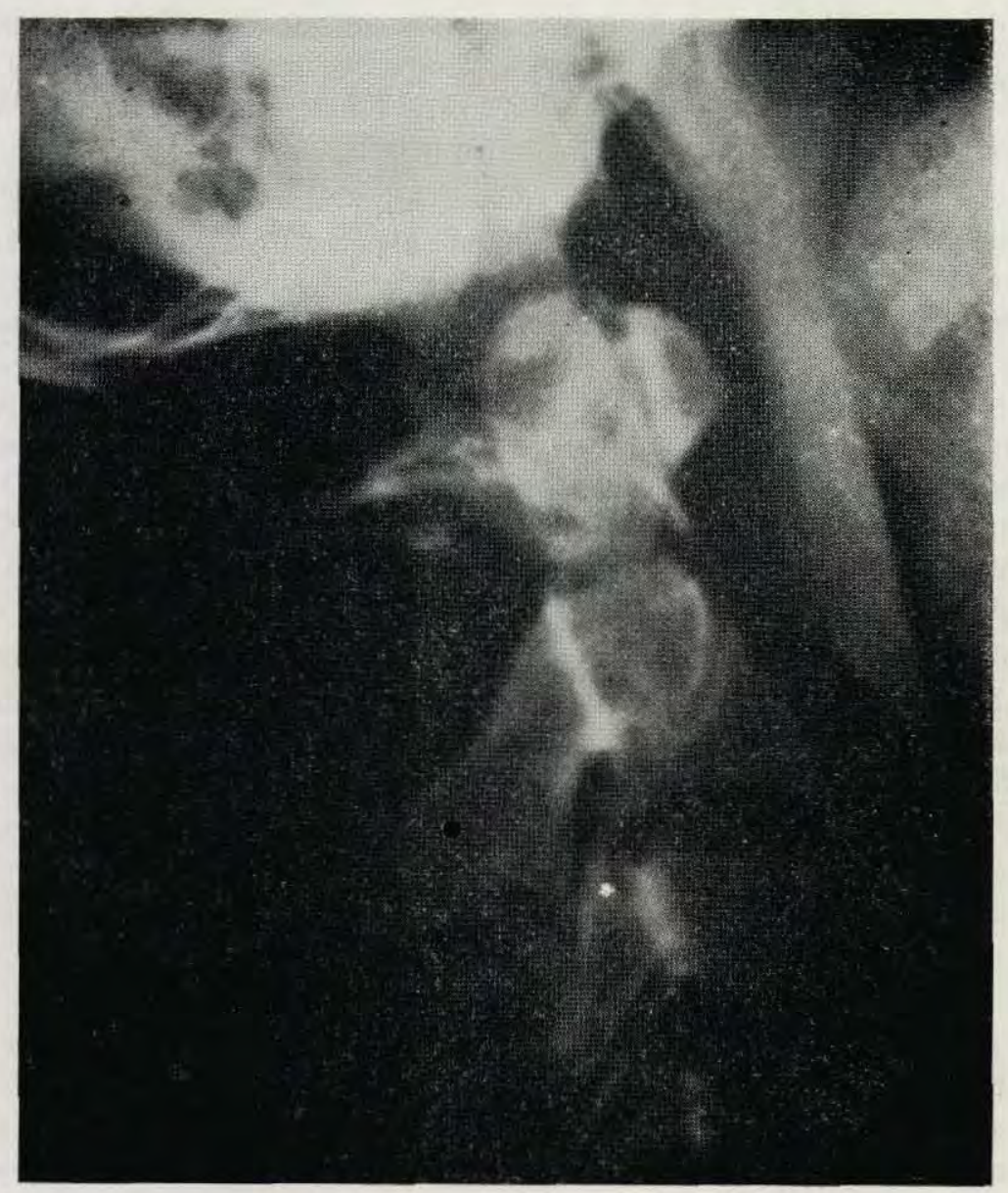

Fig. 2. Good reduction obtained after the application of skull calipers and traction.

site. They noted in their analysis of all cases to that date, that 22 of the 35 fractures of which the outcome was known, failed to unite by bone. At 67 per cent this was a high failure rate, and it was interesting to note that failure of fusion occurred in six cases treated adequately from the time of injury by traction and immobilisation.

It has been stated that firm fibrous union is compatible with safety (Blockey \& Purser, 1956, Watson-Jones, 1952) but we feel that a union which allows some movement of the odontoid, is not sufficient to stabilise the atlas and the head upon the axis in the event of sudden severe applied stresses.

Operative. Mixter \& Osgood (1910) were the first to attempt operative fixation of a fracture of the odontoid process. This case had marked forward subluxation of the atlas and severe occipital neuralgia. Treated conservatively there was no union after seven months. At operation they exposed the laminae of the upper cervical vertebrae and passed a silk ligature around the posterior arch of the atlas. The atlas was pushed into place via the pharynx and the ligature tied round the spine of the axis. The patient 
wore a leather cuirass for three months. He made a complete recovery and was reported by Osgood \& Lund (1928) twenty years after the accident as showing slight neck stiffness only; photographs showed almost complete range of rotatory movements. Ely (1911) successfully tried Mixter \& Osgood's operation on a similar case who had non-union and forward displacement nine months after the accident. This operation had later success in the hands of Tavernier (1931), Rogers (1957), Smith (1958) and Price (1960) but failed for Blockey and Purser (1956) and Forsyth et al (1959).

Kahn and Yglesias (1935) fused the occiput to the upper four cervical vertebrae and thus introduced a second operation for fixation of the unstable atlanto-axial joint. Rogers (1942), Colsen (1949), Blockey \& Purser (1956) and Norton (1962), all used this method with success.

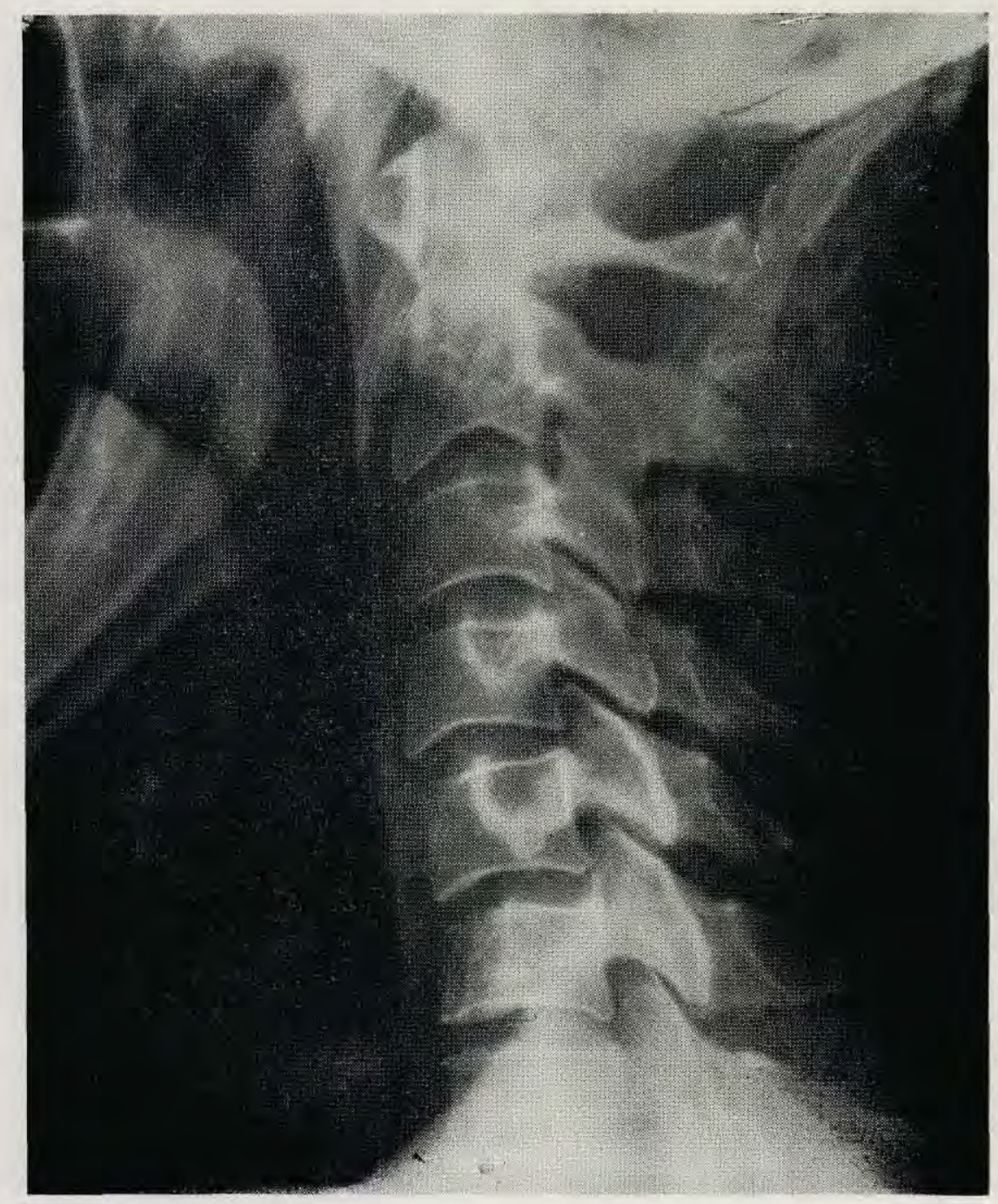

Fig. 3. The result following occipito-cervical fusion. 
Forsyth et al (1959) had 15 cases of fractured odontoid in their series of cervical fractures and dislocations. After the failure of their first 2 cases treated by atlanto-axial fusion, they turned to fusing the upper three cervical vertebrae using bone bank rib wired into place. This was successful in all 11 cases fused. Similar methods were used by Cone and Turner (1937) and Norton (1962).

Fang \& Ong (1962) introduced another new technique by approaching the atlantoaxial region through the open mouth and dividing the posterior wall of the pharynx. They fused the lateral masses of the atlas to the articular facets of the axis.

\section{Choice of Procedure}

We chose occipito-cervical fusion in preference to fusing the atlas to the axis for the following reasons:-

The procedure fuses the skull to the massive spine of the axis and thus prevents any strain falling on the unstable atlanto-axial joint. The skull, atlas and axis move in one piece and any applied stress is transmitted to the normal cervical spine lower down.

Fixing the frail arch of the atlas to the axis is mechanically weaker. If the head is allowed to move freely on the atlas, it will gain momentum in a flexion or extension injury and at the limit of free movement, a sudden strain will be applied to the weakest part of the fusion.

Blockey \& Purser (1956), Forsyth et al (1959) and our own Case 2 all demonstrated failure of atlanto-axial procedures in preventing re-subluxation.

\section{Limitation of movement}

Fielding (1957) using cineradiography showed that the following range of movements took place at the upper end of the spinal column.

Occipito-atlantal joint: Flexion 10 degrees. Extension 25 degrees.

Atlanto-axial joint:

Rotation 45 degrees, Flexion 5 degrees and Extension 10 degrees.

Total cervical movements: Flexion-Extension 90 degrees. Lateral Flexion 90 degrees. Rotation 90 degrees.

After internal fixation of the odontoid fracture, whether it be by occipito-cervical fusion or by cervical fusion alone, there is limitation of movement of the head and neck. In only four cases have the results been recorded.

Kahn \& Yglesias (1935) fused the occiput to upper five cervical vertebrae. Eighteen months later there was slight rotation, a few degrees of flexion and extension, and 10 to 15 degrees of lateral rotation. Colsen (1949) fused the occiput and upper four cervical vertebrae. One year later the movement of the head allowed was:-Flexion reduced 15 per cent, extension 30 per cent and rotation 50 per cent.

Blockey \& Purser (1956) Case 4, fused the occiput, atlas and axis. Two years later the patient " could not nod the head but there was almost full range of flexion, extension and lateral movement-rotation was possible through half the normal range".

Forsyth et al (1959) fused the atlas, axis and third cervical vertebrae and recorded the result in one of their patients one year later as " limitation of movement of 30 per cent". 

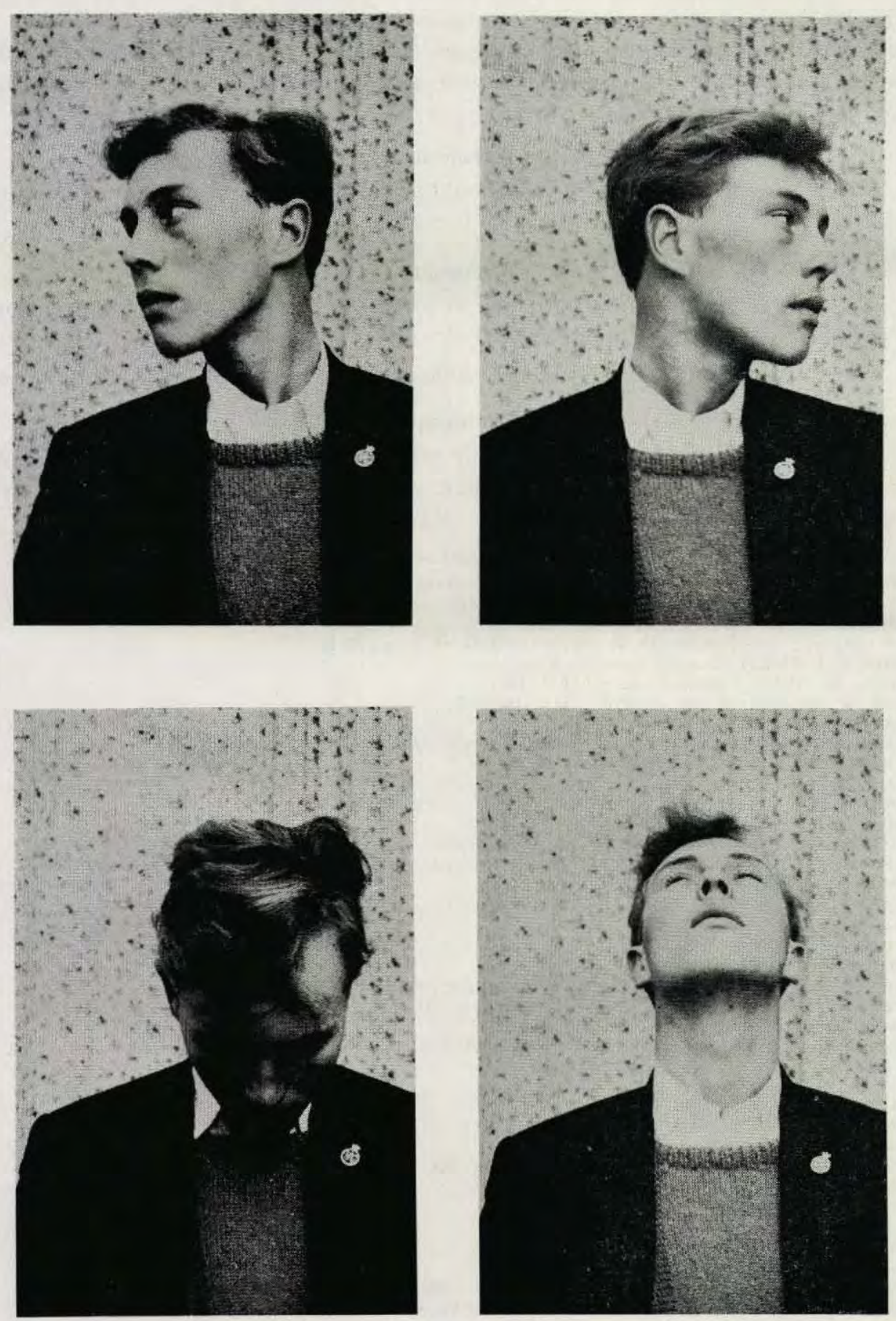

Fig. 4. Demonstration of the full total range of neck movements one year after occipito-cervical fusion, 
In a young patient, following occipito-cervical fusion, such as our own Case 1, a full total range of movements may be obtained because compensatory movements of the lower cervical spine takes place, although nodding movements are lost. In an older patient, such as Case 6 , full total movements are not regained, but a good result may leave only 30 degrees lacking in rotation.

\section{Conclusions}

Most cases of fractured odontoid should be rigidly fixed to prevent complications. Occipito-cervical fusion is a satisfactory procedure for this fixation.

\section{Summary}

Six cases of fracture of the odontoid process of the axis, five of whom were treated by occipito-cervical fusion, are described.

The cause, diagnosis, complications, methods and results of treatment are discussed.

\section{Acknowledgement}

- I would like to express my thanks to Mr. D. J. Cowan and Lieutenant-Colonel R. H. Freeman, under whose care the patients described were treated, for their help and encouragement in writing this paper.

\section{REFERENCES}

Amyes, E. W. and Anderson, F. M., (1956) Arch. Surg., Chicago, 72, 377

BAYARD, (1870) Boston med. surg. J., N.S. CXL, III

BERNSTEIN, (1903) Dtsch. Z. Chir., 70, 175

Blockey, N. J. and Purser, D. W., (1956) J. Bone Jt. Surg, 38 B, 794

CAMPS, F. E. (1965). Personal communication.

COLSEN, K. (1949). J. Bone Jt. Surg.; 31 B, 395.

CONE, W. and TuRner, W. G. (1937). Ibid, 19, 584.

Corner, E. M. (1907). Ann Surg., 45, 9.

Cortes, quoted in Malgaigne, J. F. (1855). Traite des fractures et des luxations, 2, 334,Paris.

DUPONT, (1876). Bull. Soc. med. Suisse, 10, 65.

Ely, L. W. (1911). Ann. Surg., 54, 20

FANG, H. S. Y. and ONG, G. B. (1962). J. Bone Jt. Surg., 44 A, 1588.

FIELDING, J. W. (1957). Ibid, 39 A, 1280

Fritzche, E. (1913). Disch. Z. Chir., 120, 7 and 183.

Forsyth, F. H., Alexander, E., Davis, C., Underdahl, R. (1959). J. Bone Jt. Surg. 41 A, 17.

GrBSON, W. (1885). Lancet, ii, 429.

HAMBLEN, D. L. (1967), J. Bone. Jt. Surg., 49 B, 33

Haughton, S. (1866). Philosoph. Mag., July.

JEFFERSON, G. (1920). Brit. J. Surg., 7, 407.

JEFFERSON, G. (1927). Brit. med. J., 2, 153.

Kahn, E. A. and Yglesias, L. (1935). J. Amer. med. Assoc., 105, 348.

Mixter, S. J. and Osgood, R. B. (1910). Ann. Surg., 51, 193.

NoRTON, W. L. (1962). J. Bone Jt. Surg., 44 A, 115.

Osgood, R. B. and LuND, C. C. (1928). New Engl. J. Med., 198, 61.

PILCher, L. S. (1910). Ann. Surg., 51, 208.

Price, E. (1960). J. Bone Jt. Surg., 42 B, 410.

ROGERS, W. A. (1942). Ibid, 24, 245.

ROGERS, W. A. (1957). Ibid, 39 A, 341.

SCOTT, L. B. (1904). Brit. med. J., 1, 247.

SICARD, J. A. \& Roger, H. (1916). Marseille med., 53, 449.

Simpson, K. (1961) Forensic Medicine, E. ARNold.

SMITH, S. (1871). Amer. J. med. Sc., 62, 338.

SYME, J. (1826). Edinb. med. school J., 25, 311.

TAVERNIER, L. (1931). Rev. Orthop., 18, 562.

Thompson, H. (1962). J. Bone Jt. Surg., 44, B 655.

WAGNer, W. and StolPer, P. (1898). Dtsch. Chir., 40, 309.

Watson-Jones, R. (1952). Fractures and Joint injuries, 4th Ed. E. S. Livingstone Ltd.

Whrte, R. (1966). J. Bone Jt. Surg., 48 B, 592.

Willard, D. P. and Nicholson, J. T. (1941). Ann. Surg. 113, 464.

WOOD JONES, F. (1913). Lancet, $i, 53$.

Wusthoff, R. (1923). Dtsch. Z. Chir., 183, 73. 